\title{
Minimal Local Analgesic Dose of Intrathecal Bupivacaine and Ropivacaine in Patients Undergoing Cesarean Section: A Comparative Study
}

\author{
Jeevan Singh ${ }^{\mathrm{add}, \mathrm{f}}$ Ashish Shrestha ${ }^{\mathrm{b}, \mathrm{d}, \mathrm{f}}$ Kalpana Kharbuja ${ }^{\mathrm{b}, \mathrm{d}, \mathrm{f}}$ \\ Alex Tandukar ${ }^{\mathrm{b}, \mathrm{d}, \mathrm{f}}$ Abha Shrestha ${ }^{\mathrm{ce,ef}}$
}

\begin{abstract}
:
Introduction: Spinal anesthesia is considered a reasonable option for cesarean section. Bupivacaine and ropivacaine have been used as intrathecal drugs alone or in combination with various opioids. Ropivacaine is considered a valid and safe alternative to bupivacaine for intrathecal anesthesia. This study aims to determine the median effective dose (ED50) of intrathecal bupivacaine and ropivacaine for cesarean section and defines this as the minimum local anesthetic dose (MLAD). Methods: Forty pregnant women undergoing elective cesarean section were allocated and randomized into two groups. The initial dose was $13 \mathrm{mg}$ for both ropivacaine and bupivacaine groups and was increased or decreased of $0.3 \mathrm{mg}$, using the up-down sequential allocation technique. Efficacy was accepted if adequate sensory dermatomal anesthesia to pinprick to T6 was attained within 20 minutes after intrathecal injection and required no supplemental epidural injection for procedure until at least 50 minutes after the intrathecal injection of test drugs. The MLAD for both bupivacaine and ropivacaine was calculated with 95\% confidence interval using the formula of Dixon and Massey. Comparison of different variables between the groups was done using t-test with significant $p$ value at $<0.05$. Results: The two groups were comparable in terms of demographic profile and clinical characteristics. The MLAD of ropivacaine and bupivacaine were $11.63 \mathrm{mg}$ (95\% CI, 11.5-12.92) and 10.459 mg (95\% CI, 10.12-10.87) respectively. The potency ratio between spinal ropivacaine and bupivacaine was 0.89. Conclusion: Ropivacaine provided clinically surgical anaesthesia of shorter duration without compromising neonatal outcome and can be used as a safe alternative to bupivacaine.
\end{abstract}

Keywords: Bupivacaine, Cesarean section, Ropivacaine, Spinal Anesthesia

\section{INTRODUCTION:}

Spinal anesthesia is considered a reasonable option for cesarean section. Intrathecal drugs like bupivacaine and ropivacaine have been used either alone or in combination with various opioids. Ropivacaine, a pure s-(-) enantiomer aminoamide long acting local anesthetic agent with structural

\author{
Submitted: 19 June, 2018 \\ Accepted: 04 February, 2018 \\ Published: 13 February, 2019 \\ a - Associate Professor and Head \\ $\mathrm{b}$ - Lecturer \\ c - Associate Professor \\ d - Department of Anesthesia and Critical care \\ e - Department of Obstetrics and Gynaecology \\ f - Kathmandu University School of Medical Sciences, Dhulikhel
}

Corresponding Author:

Jeevan Singh

e-mail: drjeevan25@gmail.com

ORCID: https://orcid.org/0000-0003-4319-6261 and pharmacological similarity to bupivacaine.[1] At high doses, it produces surgical anesthesia and at lower doses it produces analgesia (sensory block) with limited and non-progressive motor block. As compared to bupivacaine, the motor block is often slower in onset, shorter in duration and less potent.

In-vitro, ropivacaine has shown less cardiotoxicity than the equivalent concentration of racemic bupivacaine. It has been registered for use in intrathecal spinal anesthesia. [3, 4] A number of studies have evaluated intrathecal use of ropivacaine for obstetric and non-obstetric patients.[5,6,7,8] There is, however, a lack of comparative studies and adequate information on the analgesic and anesthetic

\footnotetext{
How to cite this article:

Singh J, Shrestha A, Kharbuja K, Tandukar A, Shrestha A. Minimal Local Analgesic Dose of Intrathecal Bupivacaine and Ropivacaine in Patients Undergoing Cesarean Section: A Comparative Study. Journal of Lumbini Medical College. 2019;7(1):5 pages. DOI: 10.22502/ JLMC.V7I1.250. Epub: 2019 Feb 13.
} 
potency of intrathecal ropivacaine and bupivacaine administration, especially in obstetric practice. This comparative study applies a model to determine the median effective dose (ED50) of intrathecal ropivacaine and bupivacaine for cesarean section and defines this as the Minimum Local Anesthetic Dose (MLAD).

\section{METHODS:}

This is a comparative, up-down sequential allocation study conducted in the Department of Anesthesiology of a tertiary hospital over a period of six months from October, 2017 to March, 2018. The ethical approval was taken from Institutional Review Committee (KUSMS/IRC 93/17) Kathmandu University School of Medical Sciences. Written informed consent was obtained from all participants of the study.

Sample size calculation was done using the formula, $\mathrm{N}=[(\mathrm{Z} 1-\alpha / 2+\mathrm{Z1}-\beta) / \mathrm{ES}] 2$ where $\mathrm{ES}=$ $(\mu 1-\mu 2) / \sigma$. Assuming estimated standard deviation $(\sigma)=0.55$, clinically important difference $(\mu 1-\mu 2)=$ 0.5 and taking $\alpha=0.05$ with desired power (1- $\beta)$ of 0.80 , the minimum sample size was calculated to be 19.34 , that is 20 in each group.

A total of 40 women scheduled for elective cesarean delivery at more than 37 weeks of gestation and ASA physical status class I or II were enrolled into the study. Indications for cesarean section included previous cesarean section, transverse lie, complete placenta previa, pregnancy with tumors in lower uterine segment and primi breech presentation. All the participants were pre-medicated with $150 \mathrm{mg}$ of ranitidine two hours before surgery. They were not given opioids during the study period.

They were divided randomly into two groups of twenty each, using a computer generated random numbers list. Intravenous access was obtained with an $18 \mathrm{G}$ cannula through which all participants were pre-loaded with a balanced crystalloid solution of one liter over ten minutes before inducing Combined Spinal Epidural (CSE). The participants were not aware of the group that they were in and the observer was also kept blinded for the study drug dose injected by the independent anesthesiologists giving CSE in the sitting position by two space CSE technique at the L3-L4 interspace. $[9,10]$ After confirming a free flow of cerebrospinal fluid(CSF), the study drug was injected at a rate of approximately $0.2 \mathrm{ml} /$ second intrathecally, to the allocated group accordingly by an anesthetist not related to the study. The dose of ropivacaine or bupivacaine in all syringes was taken by the response of the previous participant to a greater or lesser dose according to the vertical sequential allocation. The starting dose was $13 \mathrm{mg}$ for both ropivacaine and bupivacaine group. An anesthesia nurse who had no further role in the study prepared the syringes with the solution.

Sensory level to pinpricks was assessed by the Hollmen scale: $0=$ ability to appreciate a pinprick as sharp; $1=$ ability to appreciate a pinprick as less sharp; 2 = inability to appreciate a pin prick as sharp (analgesia); $3=$ inability to appreciate a pin prick as pin touching (analgesia). The participants were assessed before cesarean delivery, at skin incision, uterine incision, birth, peritoneal closure and at the end of the surgery. There were three possible outcomes. a) Effective: Women declared a Visual Analogue Pain Scale (VAPS) $\leq 30 \mathrm{~mm}$ and did not require an epidural rescue bolus; this result directed a decrease of $0.3 \mathrm{mg}$ in the dose of bupivacaine or ropivacaine for the next participant in the same group, b) Ineffective: Women reported a VAPS $30 \mathrm{~mm}$ which resulted in the administration of $10 \mathrm{ml}$ epidural 2\% lidocaine. A bupivacaine or ropivacaine $0.3 \mathrm{mg}$ increment was directed for the next patient in the same group. c) Rejected: Women reported a VAPS $30 \mathrm{~mm}$ which failed to rescue bolus or some problems with CSE occurred. This result directed a repeat of the same dose of the same drug in the same group.

The intra operative monitors used were heart rate (HR), electrocardiogram (ECG), non-invasive blood pressure (NIBP) and oxygen saturation (SpO2). A consultant anesthesiologist on duty on the day of study period recorded these parameters before intrathecal injection and at three minutes interval until delivery, then every five minutes through surgery. Maternal hypotension was defined as a $20 \%$ reduction in systolic arterial pressure from baseline values and was treated promptly with intravenous ephedrine 10mg. During intra-operative period, the onset of action time in both the drugs was noted from incision up to closure of skin and postoperative complications like hypotension, nausea and vomiting were noted.

The data collection was done mainly using the questionnaire which was filled up by the anesthesiologists regarding level of block, pain score using visual analogue scale, duration of anesthesia, hypotensive effect and post-operative nausea and 
vomiting. Patient and obstetrics data were tabulated into Microsoft Excel and analyzed with the Statistical Package for Social Sciences (SPSS ${ }^{\mathrm{TM}}$ ) version 21. It was presented as mean (+SD), Median (IQR) and was analyzed using analysis of variance and Chisquare test respectively.

The significance of difference between two groups was evaluated by student's t test. The significance level for all tests was set at $p<0.05$. The MLAD for both bupivacaine and ropivacaine was calculated with $95 \%$ confidence interval using the formula of Dixon and Massey.

\section{RESULT:}

A total of 40 consecutive eligible participants, enrolled into the study, were randomized into two study groups. The groups were comparable in terms of patient characteristics (age, weight, duration of surgery, ASA grade, APGAR score and the gestational age), and baseline vital parameters. The anesthetic and surgical techniques were standardized for both groups. The new born babies had a mean APGAR score $( \pm$ SD) of $9.0( \pm 0.20)$ and $9.5( \pm 0.35)$ at five minutes in the bupivacaine and ropivacaine groups respectively (Table 1).

The intrathecal MLAD $(95 \%$ CI $)$ of ropivacaine was $11.6 \mathrm{mg}(11.2-12.6 \mathrm{mg})$ and that of bupivacaine was $11.25 \mathrm{mg} \quad(10.0-12.5 \mathrm{mg})$, using the formula of Dixon and Massey (Figures 1 and 2). The relative potency ratio between spinal ropivacaine and bupivacaine was 0.90 . Anesthesia was successfully performed within the predetermined criteria in all 20 patients in both groups. The participants labelled 'ineffective' were pain free at skin incision or at delivery, but required supplementary analgesia at peritoneal closure. All patients who required

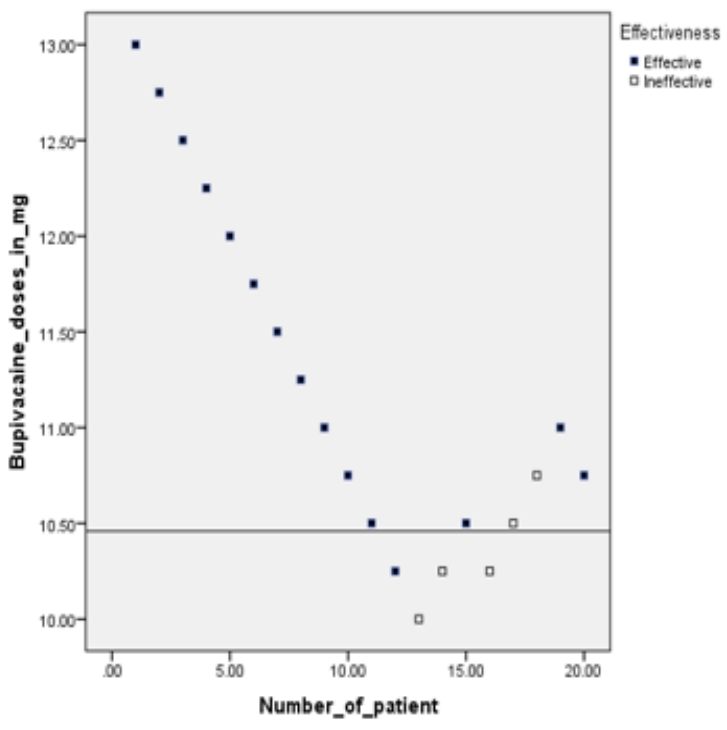

Figure 1. The MLAD of bupivacaine for cesarean section was $10.459 \mathrm{mg}$ (CI 95\%: 10.12-10.87)), using the formula of Dixon and Massey.

epidural top-ups obtained good pain relief. The mean MAP decreased significantly in both the groups compared to baseline/pre-operative values $(p<0.005)$. The percentage of participants with hypotension was $36.5 \%$ in the ropivacaine and $60 \%$ in the bupivacaine group. The results were statistically significant both with $\mathrm{p}=0.032$. Bradycardia occurred during intra-operative period in two patients in each group. There were no significant differences between the two groups with respect to respiratory rate and oxygen saturation. Eight participants in bupivacaine group and six in ropivacaine group required ephedrine for correction of hypotension. Three participants in ropivacaine and five in bupivacaine group required ondansetron

Table 1. Comparison of demographic profile, clinical characteristics and neonatal outcome between the study groups (N=40)

\begin{tabular}{lccc}
\hline Variables & $\begin{array}{c}\text { Ropivacaine group } \\
(\mathbf{n}=\mathbf{2 0})\end{array}$ & $\begin{array}{c}\text { Bupivacaine group } \\
(\mathbf{n}=\mathbf{2 0})\end{array}$ & P-value \\
\hline Age in years, mean \pm SD & $26.7 \pm 5.3$ & $25.4 \pm 4.7$ & $>0.05$ \\
\hline Weight in kg, mean \pm SD & $58.2 \pm 7.2$ & $60.3 \pm 8.3$ & $>0.05$ \\
\hline Height in cm, mean \pm SD & $153 \pm 6.5$ & $152 \pm 5.5$ & $>0.05$ \\
\hline ASA grade (I/II) & $16 / 4$ & $17 / 3$ & $>0.05$ \\
\hline Duration of surgery in minutes, mean \pm SD & $52 \pm 7.0$ & $56 \pm 6.0$ & $>0.05$ \\
\hline APGAR Score at 5 minutes, mean \pm SD & $9 \pm 0.20$ & $9.5 \pm 0.35$ & $>0.05$ \\
\hline Gestational age in weeks, mean \pm SD & $37.2 \pm 1.4$ & $37.8 \pm 1.8$ & $>0.05$ \\
\hline
\end{tabular}




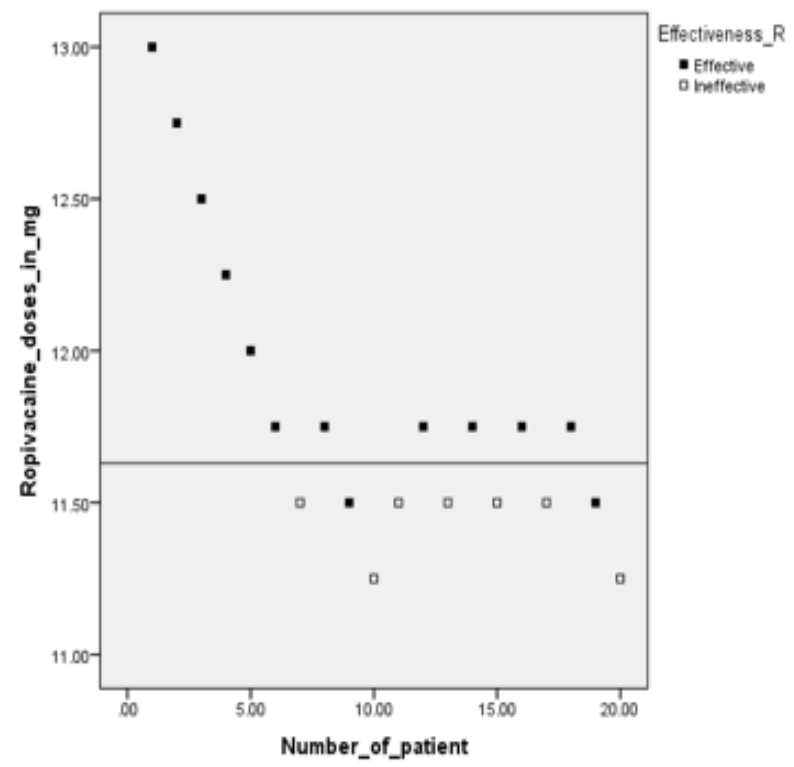

Figure 2. The MLAD of ropivacaine for caesarean section was $11.63 \mathrm{mg}$ (95\%CI, 11.5-12.92) using the formula of Dixon and Massey

for correction of vomiting. Incidence of hypotension, consumption of ephedrine and episodes of nausea and vomiting were similar between the groups.

\section{DISCUSSION:}

The MLAD model has been used in the investigation of analgesic requirements in labour. [11] A relatively recent concept of minimum local anesthetic concentration determines the median effective dose and potencies of local anesthetics for spinal anesthesia.[12] A study by Stocks et al.[13] established the MLAD of intrathecal bupivacaine in parturients to determine the minimum local analgesic concentration of epidural local anesthetic.

In our study, we used the sequential allocation design for cesarean section to discover any difference in the estimation of the ED50 found in previous clinical studies with other statistical method. Khaw et al.[6], in his dose response study with plain spinal ropivacaine for cesarean delivery, determined the effective doses for ED50 to be $16.5 \mathrm{mg}$ ( $95 \% \mathrm{CI}, 14.1$ -18.8) and ED95 to be $26.8 \mathrm{mg}$ (95\% CI, 23.6-34.1).

In another study done by Celleno et al. [14], the ED50 of plain ropivacaine for cesarean section was reported to be $14.22 \mathrm{mg}$. This study showed a higher ED50 than ours. We attributed this difference to density of ropivacaine solutions administered intrathecally. The ropivacaine solution used in this study was isobaric where as that used in previous studies was hyperbaric. The feature of the neuraxial block during spinal anesthesia depends on the baricity, and the position of the patient. In parturients, while performing spinal anesthesia in lateral position the level of head is lower than the hip as the width of hips is usually larger than the shoulders in women. Further more, during pregnancy the gap is even higher. During the hyperbaric solution injection, in lateral position, the drug solution moves cephalad due to gravity. Unlike hyperbaric, isobaric solution is not affected by the gravity. In order to avoid the spread, this hyperbaric solution in our study was given in a sitting position.

In our study, we found the MLAD of bupivacaine was $11.25 \mathrm{mg}$ and ropivacaine was $11.6 \mathrm{mg}$. This finding was similar to the study done in Meerut by Singh S et al. where MLAD of $0.5 \%$ of hyperbaric bupivacaine was $12.5 \mathrm{mg}$ and for $0.75 \%$ isobaric ropivacaine, it was $24 \mathrm{mg}$.[15] However in their study, they used $0.75 \%$ isobaric ropivacaine whereas, we used $0.5 \%$ isobaric ropivacaine. In a similar study done by Tadeusz et al. [16] in Poland and Fei Xiao et al. [17] in China, the MLADs of intrathecal ropivacaine and bupivacaine for cesarean delivery were reported $9.45 \mathrm{mg}$ and 7.33 respectively. These results are consistent with the present study with only difference that they performed spinal anesthesia in L2-3 space whereas we performed in L3-4 space.

In another study done in Peking University by Geng Zhi-yu et al.,[18] the intrathecal MLAD was $9.45 \mathrm{mg}$ (95\% CI, 8.45-10.56mg) for ropivacaine and $7.53 \mathrm{mg}(95 \% \mathrm{CI}, 7.00-8.10 \mathrm{mg})$ for bupivacaine. This was slightly less than that found in our study. This difference can be attributed to the density of ropivacaine and bupivacaine. Likewise, a similar study done in Lucknow by Gupta A et al.[19] had found the MLAD of ropivacaine was $12.5 \mathrm{mg}$ in combination with $25 \mathrm{mg}$ of fentanyl which is consistent with our study.

Similar to our study, another study by Whiteside et al. comparing $15 \mathrm{mg}$ of $0.5 \%$ ropivacaine or $0.5 \%$ bupivacaine in $8 \%$ glucose, reported that ropivacaine was reliable for spinal anaesthesia for lesser duration and with lesser hypotension than bupivacaine.[20] Another study by McNamee et al.[21] reported intrathecal administration of 17.5 mg plain ropivacaine $0.5 \%$ or plain bupivacine $0.5 \%$ also had similar effective spinal anesthesia for total hip arthroplasty.[21]

\section{CONCLUSION:}


For elective cesarean delivery under spinal anesthesia, $11.6 \mathrm{mg}$ of $0.5 \%$ isobaric ropivacaine is an effective and safe alternative to bupivacaine. Ropivacaine provided clinically surgical anaesthesia of shorter duration without compromising neonatal outcome.

\section{REFERENCES:}

1. Collis RE, Davies DW, Aveling W. Randomised comparison of combined spinal-epidural and standard epidural analgesia in labour. Lancet. 1995;345(8962):14136. PMID: 7760614

2. Richardson MG, Thakur R, Abramowicz JS, Wissler RN. Maternal posture influences the extent of sensory block produced by intrathecal dextrose-free bupivacaine with fentanyl for labor analgesia. Anesthesia \& Analgesia. 1996;83(6):1229-33. PMID: 8942591

3. Malinovsky JM, Charles F, Kick O, Lepage JY, Malinge M, Cozian A, et al. Intrathecal anesthesia: ropivacaine versus bupivacaine. Anesthesia \& Analgesia. 2000;91(6):1457-60. PMID: 11094000

4. Wille M. Intrathecal use of ropivacaine: a review. Acta Anaesthesiologica Belgica. 2004;55(3):251-9. PMID: 15515303

5. Chung CJ, Choi SR, Yeo KH, Park HS, Lee SI, Chin YJ. Hyperbaric spinal ropivacaine for cesarean delivery: a comparision to hyperbaric bupivacaine. Anesthesia \& Analgesia. 2001;93(1):157-61. PMID: 11429357

6. Khaw KS, NganKee WD, Wong M, Ng F, Lee A. Spinal ropivacaine for cesarean delivery: a comparison of hyperbaric and plain solutions. Anesthesia \& Analgesia. 2002;94(3):680-5. PMID: 11867397

7. Danelli G, Fanelli G, Berti M, Cornini A, Lacava L, Nuzzi $\mathrm{M}$, et al. Spinal ropivacaine or bupivacaine for cesarean delivery: a prospective, randomized, double-blind comparison. Regional Anesthesia and Pain Medicine. 2004;29(3): 221-6. PMID: 15138906

8. Kallio H, Snall EV, Kero MP, Rosenberg PH. A comparison of intrathecal plain solution containing Ropivacaine 20 or $15 \mathrm{mg}$ versus bupivacaine $10 \mathrm{mg}$. Anesthesia \& Analgesia. 2004;99(3):713-7. PMID: 15333400

9. VanKleef JW, Veering BT, Burn AG. Spinal anesthesia with ropivacaine: a double-blind study on the efficacy and safety of $0.5 \%$ and $0.75 \%$ solution in patients undergoing minor lower limb surgery. Anesthesia and Analgesia. 1994;78(6):1125-30. PMID: 8198269

10. McDonald SB, Liu SS, Kopacz DJ, Stephenson CA. Hyperbaric spinal ropivacaine: a comparison bupivacaine in volunteers. Anesthesiology. 1999;90(4):971-7. PMID: 10201665

11. Lacassie HJ, Columb MO, Lacassie HP, Lantadilla RA. The relative motor blocking potencies of epidural bupivacaine and ropivacaine in labor. Anesthesia \& Analgesia. 2002;95(1);204-8. PMID: 12088969

\section{Conflict of interest:}

The authors declare that no competing interests exist.

\section{Source of funds:}

No funds were available.
12. Copagna G, Parpaglioni R, Lyons G, Columb M, Celleno D. Minimum analgesic dose of epidural sufentanil for firststage labor analgesia: A comparison between spontaneous and prostaglandin-induced labors in nulliparous women. Anesthesiology.2001;94(5): 740-4. PMID: 11388522

13. Stocks GM, Hallworth SP, Fernando R, England AJ, Columb MO, Gordon L. Minimum local analgesic dose of intrathecal bupivacaine in labor and the effect of intrathecal fentanyl. Anesthesiology. 2001;94(4):593-8. PMID: 11379678. DOI: 10.1097/00000542-20010400000011

14. Celleno D, Parpaglioni R, Frigo MG, Barbati G. Intrathecal levobupivacaine and ropivacaine for cesarean section. New perspectives. 2005;71(9):521-5. PMID: 16166911

15. Singh S, Singh VP, Jain M, Gupta K, Rastogi B, Abrol S. Intrathecal $0.75 \%$ Isobaric Ropivacaine Versus $0.5 \%$ Heavy Bupivacaine for Elective Casarean Delivery: A Randomized Controlled Trial. Journal of Pakistan Medical Student. 2012;2(2):75-80.

16. Kasza T, Knapik P, Misiolek H, Knapik D. Comparison of spinal anaesthesia with $0.75 \%$ ropivacaine and $0.5 \%$ bupivacaine for elective caesarean section. Annales Academiae Medicae Silesiensis. 2009;63(6):15-22.

17. Xiao F, Xu WP, Zhang YF, Liu L, Liu X, Wang LZ. The dose-response of Intrathecal Ropivacaine Co-administerd with Sufentanyl for Cesarean Delivery under Combined Spinal-epidural Anesthesia in Patients with Scarred Uterus. 2015;128(19):2577-82. PMID: 26415793. DOI:10.4103/0366-6999.166036

18. Geng ZY, Wang DX and Wu XM. Minimum effective local anesthetic dose of intrathecal hyperbaric ropivacaine and bupivacaine for cesarean section. Chinese Medical Journal 2011;124(4):509-513. PMID: 21362272

19. Gupta A, Bogra J, Singh PK, Kushwaha JK and Srivastava P. Randomized Double-Blinded Dose Response Study of the Fentanyl with Hyperbaric Ropivacaine in Cesarean Section. Journal of Anesthesia \& Clinical Research. 2014;5(11):467. DOI:10.4172/2155-6148.1000467

20. Whiteside JB, Burke D, Wildsmith JAW. Comparison of ropivacaine $0.5 \%$ (in glucose $5 \%$ ) with bupivacaine $0.5 \%$ (in glucose $8 \%$ ) for spinal anaesthesia for elective surgery. British Journal of Anaesthesia. 2003;90(3):304-8. PMID: 12594141. DOI: https://doi.org/10.1093/bja/aeg077

21. McNamee DA, McClelland Am, Scott S, Milligan KR, Westman L, Gustafsson U. Spinal Anaesthetic: comparison of plain ropivacaine $5 \mathrm{mg} / \mathrm{ml}$ with bupivacaine $5 \mathrm{mg} / \mathrm{ml}$ for major orthopedic surgery. British Journal of Anaesthesia. 2012;89(5):702-6. DOI: 10.1093/bja/aef259 